\title{
Dispositional factors of personality professional development of the future teachers of physical education and sport
}

\author{
Stepanchenko N. I. ${ }^{\mathrm{ABCDE}}$, Briskin Y.A. ${ }^{\mathrm{CDE}}$ \\ Lviv State University of Physical Culture named after I. Bobersky, Ukraine
}

Author's Contribution: A - Study design; B - Data collection; C - Statistical analysis; D - Manuscript preparation; E - Funds collection.

\begin{abstract}
Purpose: $\quad$ The relevance of the problem of professional development of teachers led to the emergence of a large number of publications on this topic in the literature. But these publications do not clarify this very complex phenomenon and do not encourage the emergence of new scientific problems. This has determined the research interest. It is based on the need to clarify idea of internal factors on an intrapersonal level that contribute to the effective professional development of future physical education and sport teachers. The purpose of the work is to study them.

Material: $\quad$ Study participants were students from four Physical Education Faculties (physical education, sports, physical therapy and tourism) of higher education in the field of physical education in Western Ukraine. A total of 356 students participated in the study of internal factors on an intrapersonal level. The choice of research sample was random, the age of students - 18-19 years old. We used the questionnaire to determine the correlation between the two signalling systems and to determine the temperamental characteristics of students. To gather and analyze data we used the quantitative method.

Results: $\quad$ Result showed that the second signalling system dominates in the majority of surveyed students. Most of the students with the prevailing second signalling system belong to the faculty of tourism (74\%). We have determined the average level of the intellectual development sphere for all students without any exceptions. The highest rates were identified for the students of physical therapy faculty. The future teachers of physical education and sport showed the lowest results in communicative sphere. This is insufficient for professional and pedagogical activity. This group of students showed the best development in psychomotor qualities, even though the results were on average level. In general, we have not determined any significant discrepancies in psychomotor, intellectual and communicative spheres of the future teachers of physical education and sports in comparison with the students of other areas of training.

Conclusions: We have demonstrated that the properties of the various personality aspects of the future physical education and sports teacher in the intellectual and communication domains are insufficient for professional work. They require the development of targeted effective methods for professional education and psycho-pedagogical means of motivation. The results of internal factors of students' personality professional development diagnostics are supported by compliance of their characterological features to the professional demands but also by the conscious professional interests.

Keywords: physical education and sport, students, professional development, factors.
\end{abstract}

\section{Introduction}

Productive work of each individual educational establishment, and the educational system in general, is only possible under corresponding socio-pedagogical circumstances created by various factors that influence the learning process [1]. Praxeologists divide these factors into internal (dispositional) and external (situational) factors [2].

The set of influences can be represented as a multilevel structure. Internal (dispositional) factors are divided into two groups: directional factors that determine the emotional and motivational aspects of a student's personality [3] and instrumental factors, which influence the intellectual and psychomotor aspects of personality $[4,5]$. The effectiveness of the educational process also determines the various external (situational) factors. These circumstances and the situations in which education is provided: the educational environment, social and material conditions, as well as the material and technical facilities of the institution and educational and

\footnotetext{
(c) Stepanchenko N. I., Briskin Y.A., 2019

doi:10.15561/20755279.2019.0407
}

methodological support for the educational process $[6,7]$.

We believe that pedagogical factors are determined by the object of research and should be divided by their relation to the educational system into external (societal-social, socio-cultural, legal, etc.) and internal (institutional-educational, methodological, contentrelated, organizational, and technological, etc.) Personality-related factors (intrapersonal-internal in relation to subjects of learning or subject matter) are internal factors [8] for improving their qualities and properties [9]. They are divided into developmental factors of the teacher and student's personality. External factors that are related to the subjects of education are interpersonal factors that affect the student in the process of learning by the faculty, peers, and mentors during the course of training, etc.

Therefore, we can say that the factors of professional development of a teacher's personality in higher educational institutions and faculties of physical education and sports are:

External in relation to the educational system of 
physical education teacher training (situational, societal) factors - communal, socio-cultural, legal, educational, environmental, etc.).

External (interpersonal) developmental factors of the student - factors that interpersonally influence the future physical education teacher by other teachers, coaches, peers, and mentors during the course of training, etc. It should be noted that some professional developmental factors of one's personality act on the personality and shape it at the stage of career choice. This often occurs under the influence of one's parents, friends, and peers.

Among the external (societal and interpersonal) factors that affect the professional development of students of high educational establishments of physical education and sports, the most important are the peculiarities of pedagogical work of a physical education teacher [10]. These include: the complexity of regulation and planning of activities, the need to show creativity; lack of material and results of labour; the length of communication between the teacher and the students; a variety of functional duties performed (sports, physical education, pedagogical, educational, health education, prophylactic and preventive, design-planning, organizational-managerial, operational-technological, evaluation-control, research, etc.).

Internal (institutional) influential factors in higher education institutions of physical education and sports, where teachers are trained: material and financial, sanitary-hygienic, scientific-methodological, educationalmethodological, procedural-substantive, organizational and technological, etc. These include the educational environment of teacher training, the social and material conditions teachers' and students' activities, the degree integration of science and educational experience in the institution, qualification level of staff, support teacher creativity from colleagues and school administration, etc.

Personality (internal, dispositional, intrapersonal) factors of professional teacher development are readiness and potential of science and pedagogical workers, quality of their work, level of coordination of actions, degree of application of new concepts and principles of education, etc.

Individual developmental factors of students are directional (individual traits and qualities, and personal qualities: motives, interests, inclinations, abilities, psychological, moral and spiritual values and beliefs, etc.) and instrumental (affect perceptual processes, intellectual and psychomotor aspects of a future teacher's personality). It is important to concentrate on the values of education and motives, which help one engage in selfdiscipline and self-education, awareness of a physical education teacher's role in society. From our experience, the instrumental and directional factors that concentrate around the intellectual and emotional-motivational qualities of the future teacher have the most significant impact, because they form the totality of socially and professionally important personal qualities.

The analyzed factors correspond to the expected process of updating the characteristics of education and indicate their importance [11]. The relevance of the problem of professional development of teachers led to the emergence of many publications on this topic in the literature $[12,13]$. However, these publications not only do not clarify this very complex phenomenon, but also encourage the emergence of new scientific problems. This has determined the research interest, which is based on the need to clarify idea of internal factors on an intrapersonal level that contribute to the effective professional development of future physical education teachers. The purpose of the work is to study them.

\section{Material and Methods}

\section{Participants:}

Students of Drogobych Ivan Franko State Pedagogical University - four academical groups of two faculties (physical education and physical therapy) in the amount of 120 respondents and students of Lviv State University of Physical Culture - seven groups in the amount of 236 respondents of four faculties (physical education, sports, physical therapy and tourism) participated in the study of internal factors on an intrapersonal level. In total we have interviewed 356 students. The choice of research sample was random, the age of students - 18-19 years old.

Procedure:

Testing was conducted in September-December 2016. The testing procedure has been carried out for 16 weeks at the Universities premises. To analyze the qualities of students who master the pedagogical profession, in comparison with other future specialists in the field of physical culture and sports, we used a questionnaire by Kadyrov to determine the correlation between the two signalling systems in terms of: dynamic features (activity and self-regulation); emotionality and volition; cognitive processes: memory, imagination, thought process [14]. This method consists of 7 scales, 57 questions-statements, average time of testing 20-25 minutes.

To determine the temperamental characteristics of students, we used the method (structure of temperament questionnaire by Rusalov) which allows to determine the properties of subject-activity, intellectual, and communicative aspects of temperament [15]. The content of the questionnaire corresponds to the fourblock structure of the functional system, which consists of ergicity, plasticity, pace, and emotional sensitivity. The questionnaire consists of 105 questions and is not restricted in time. We have investigated formal-dynamic properties of the students' individuality in psychomotor, intellectual, and communicative activities. Interpretation of the survey results was based on a scale: low (0-3 points), medium (4-8 points) and high (9-12) levels. The used methods of psychodiagnostics possess retesting validity and reliability.

\section{Statistical Analysis}

The collected data were analyzed through percentage, arithmetic mean, standard deviation, Analysis of Variance (ANOVA) model, the significance level equals 0.05 . 


\section{Results}

To evaluate the potential components of professional development of the future teacher of physical education, we consider it important to study the influence of a group of internal factors of the intrapersonal level, namely, individual (congenital) and personality (acquired) personality traits.

The results of the correlational study of the two signalling systems in students of the pedagogical profession, compared with other future physical therapy and tourism specialists, are presented in Fig. 1.

As shown in Fig. 1, the first signalling system dominates in approximately a quarter of students that took part in the survey. Most of the students with the prevailing second signalling system belong to the faculty of tourism $(74 \%)$.

A comparative analysis of obtained results of indicators of psychomotor, intellectual, and communication domain of student activity shows how they change according to the domain (Table 1). The highest rates of the realization of psychomotor ergicity $(7,7 \pm 0,3)$, plasticity $(7,0 \pm 0,5)$, pace $(9,3 \pm 0,4)$ were found among the students of physical education and sport faculty. These rates comply with the average level, and psychomotor pace complies with high level of development. The lowest rates of psychomotor emotionality $(3,4 \pm 0,3)$ were recorded among students of

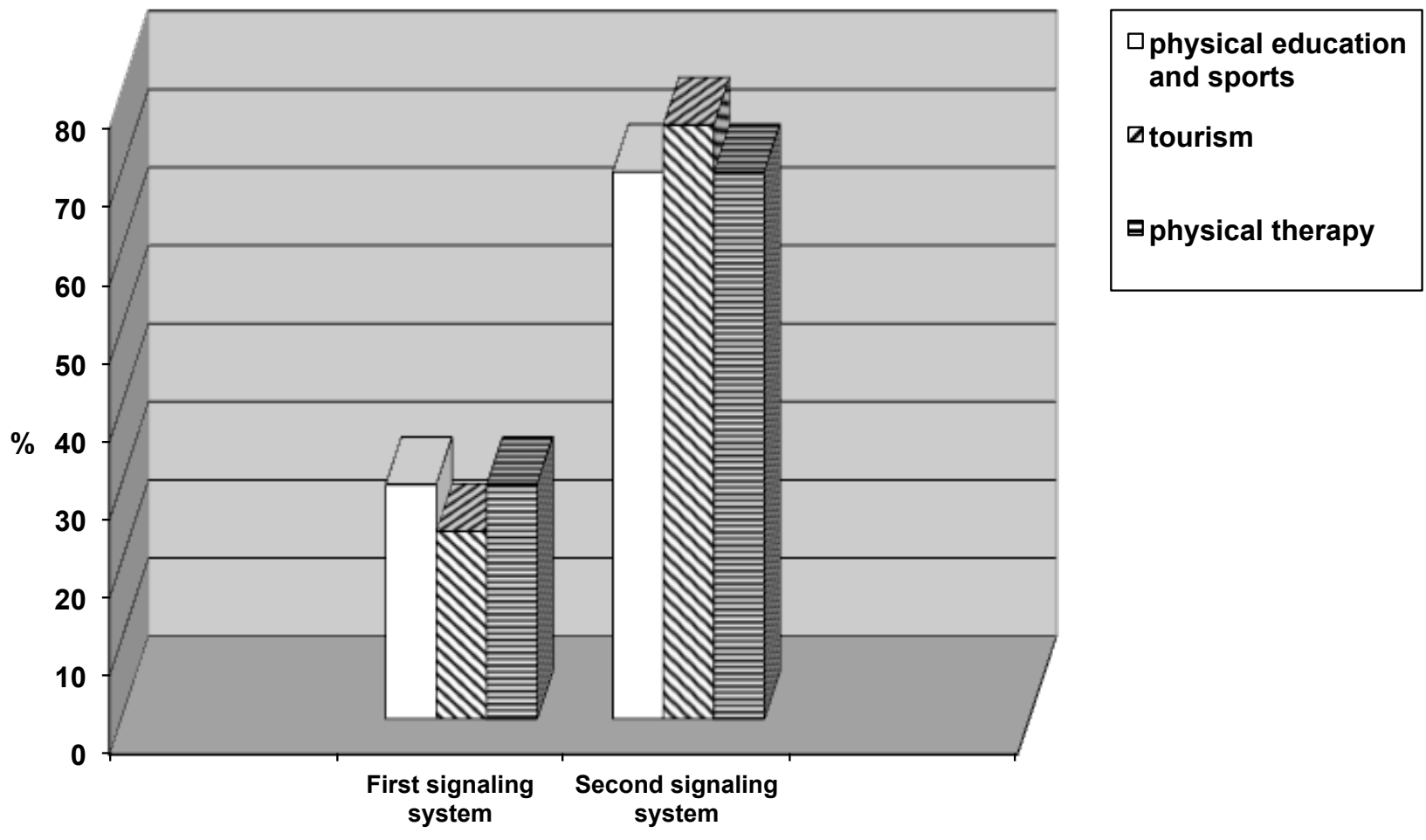

Fig. 1. Correlation of both signalling systems in students of different learning domains (in percentage)

Table 1. Properties of psychomotor, intellectual, and communicative fields in students of different domains of physical education and sports (in points, mean, standard deviation)

\begin{tabular}{lcccc}
\hline Faculty, domain of activity & \multicolumn{2}{l}{ Indicators (average points) } & & \\
& Ergicity & Plasticity & Pace & Emotionality \\
\hline Physical education and sports $(\mathrm{n}=153):$ & & & & \\
psychomotor & $7.7 \pm 0.3$ & $7.1 \pm 0.5$ & $9.3 \pm 0.4$ & $6.8 \pm 0.2$ \\
intellectual & $6.8 \pm 0.5$ & $6,0 \pm 0.5$ & $5.7 \pm 0.5$ & $7.7 \pm 0.3$ \\
communication & $7.4 \pm 0.6$ & $5.9 \pm 0.3$ & $4.1 \pm 0.6$ & $7.0 \pm 0.4$ \\
Tourism (n=92): & & & & \\
psychomotor & $7.0 \pm 0.4$ & $4.5 \pm 0.4$ & $6.4 \pm 0.3$ & $7.7 \pm 0.3$ \\
intellectual & $6.6 \pm 0.3$ & $4.1 \pm 0.3$ & $7.9 \pm 0.4$ & $6.4 \pm 0.5$ \\
communication & $7.4 \pm 0.7$ & $5.6 \pm 0.5$ & $7.6 \pm 0.5$ & $6.7 \pm 0.6$ \\
Physical therapy (n=111): & & & & \\
psychomotor & & & $3.4 \pm 0.3$ \\
intellectual & $7.4 \pm 0.5$ & $6.8 \pm 0.2$ & $9.9 \pm 0.5$ & $5.5 \pm 0.3$ \\
communication & $8.3 \pm 0.3$ & $6.3 \pm 0.3$ & $9.6 \pm 0.2$ & $4.8 \pm 0.2$ \\
\hline
\end{tabular}


Table 2. Comparison of formal dynamic properties of students in different fields (in points, mean, standard deviation)

\begin{tabular}{llll}
\hline Faculty & \multicolumn{2}{l}{ Field of activity (in points) } \\
& Psychomotor & Intellectual & Communicative \\
\hline $\begin{array}{l}\text { Physical education and } \\
\text { sports ( } \mathrm{n}=153)\end{array}$ & $7.7 \pm 0.4$ & $6.6 \pm 0.5$ & $6.1 \pm 0.5$ \\
Tourism ( $\mathrm{n}=92)$ & $6.4 \pm 0.4$ & $6.3 \pm 0.4$ & $6.8 \pm 0.6$ \\
Physical therapy $(\mathrm{n}=111)$ & $6.9 \pm 0.4$ & $7.4 \pm 0.3$ & $7.3 \pm 0.4$ \\
\hline
\end{tabular}

physical therapy faculty.

The best results of emotional ergicity and pace were detected among future rehabilitation specialists $(8,3 \pm 0,3$ and $9,6 \pm 0,2)$. Also, the most developed communicative component we have found between the students of physiotherapy faculty. The future rehabilitation specialists are characterized by the lowest development level of emotionality.

Comparing the formal dynamical peculiarities of the future specialists we have to notice the average level of intellectual sphere development among all students without exceptions. The highest rates we have determined among the students of the physiotherapy faculty $(7,4 \pm 0,3)$. The lowest results in communicative sphere were shown by the future teachers of physical education and sport $(6,1 \pm 0,5)$. This is not meeting the demands of the profession. In general, the survey has not determined any significant discrepancies in psychomotor, intellectual and communicative spheres of the future teachers of physical education and sport in comparison with the students of other areas of training $(\mathrm{F}=2,14$ at critical values 5,14 for the significance of 0,05$)$.

\section{Discussion}

In the beginning of our discussion we would like to stress that we have not found any relevant researches made on the matter of our work to be able to compare the results received by us.

The fact that the second signalling system dominates in most surveyed students gives us ground to attribute their personality type as "intellectual", which is a combination of "intelligence and volition". This is of utmost importance for future teachers because it is based on volitional regulation of activity. In the professional work of specialists in physical education and sports, volitional expression not only allows one to overcome internal and external obstacles by achieving set goals, but it is also the basis of forming an individual style of volitional activity.

We consider high levels of ergicity and plasticity to be optimal for successful professional activity of physical education and sports specialists; medium and high rates of pace; low and medium levels of emotional sensitivity. The highest indicator of the use of psychomotor ergicity was found in students in the physical education and sports field. This is considered average - students have normal muscle tone, full range of motion, and average muscle performance. All students had average development using the "plasticity" indicator. This is characterized by flexibility when switching from one form of physical activity to another, average penchant for various forms of motor activity. The level of development of mental and physical endurance (ergicity) and the ability to adapt easily to the new conditions (plasticity) are not sufficient for the future physical education and sports specialists.

A high level of psychomotor pace (speed) we have seen in students of physical education and sports. These students are characterized by a fast pace of psychomotor behavior and physical activity. The high indicators in the physical therapy group of students can be explained by the significant number of students that do sports while studying in this field. All surveyed students showed average levels of psychomotor emotionality expression. This is characterized by normal intensity of emotional response in event of failure in manual labour and physical work. Overall, all students had average psychomotor activity.

We have established by an analysis of the intellectual domain the average level of formal dynamic properties for students in physical education and sports faculties. Intellectual emotionality is used on an average level in event of emotional experiences due to failure of intellectual activity. Regarding ergicity, there was an average level of intellectual capabilities and focus on activities that require intellectual strain.

Future teachers of physical education and coaches from various sports have an average level of intellectual plasticity that manifests in various forms of intellectual activity. They have an average cognitive processing speed when performing mental operations.

We have determined that properties of the intellectual domain are more evident in students in physical therapy faculties. The highest level in this group of students was speed (pace). This same group of students had the highest indicators of intellectual ergicity and plasticity. Overall, the results of the survey showed that properties of the intellectual domain among all students are mostly average.

We have also analyzed the communication domain of student individuality that also showed average levels. This indicates that there is a need for communication and moderate communicability. Additionally, students of physical education and sports faculties had lower levels of communication speed than students in other fields. It is obvious that the high development level of intellectual and communicational abilities is crucial 
for effective professional activity of future physical education teachers and coaches. We consider that the psychodiagnostic methods should be used during the selection of this faculties' future students. These methods should determine future students' intellectual level and communicational abilities.

The overall results in the communication domain indicate that students in physical education and sports faculties do no differ greatly from other fields.

Analysis of formal dynamic properties of students in different fields gives us grounds to state that based on psychomotor domain indicators, future physical education teachers and coaches do not have a great need for psychomotor activity. But they require it on a higher level compared to other students. At the same time, physical education teachers have an assumed higher requirement for the development of physical qualities, proper lifestyle and maintaining these over the course of their life. Various aspects of temperament in physical education and sports faculty students, like the dynamic side of students' personalities, demonstrate a need to increase psycho-pedagogical influence, particularly of motivational nature.

The average intellectual domain figures we obtained indicate that students in the physical education and sports faculties have insufficient levels for successful professional pedagogical work after finishing studies. As researchers have noted, the level of intellectual properties correlates with the didactic pedagogical abilities of a teacher, provides understanding of professional tasks, determination of their significance, and the search for ways to solve pedagogical situations. Therefore, the development of the intellectual domain should grow due to the nature of professional activity in the future.

The communication component in physical education and sports teachers is characterized by a stable focus on performing pedagogical work. That is why developing this component, which showed the lowest levels in our study, for future teachers of physical education and sports, coaches are vital.

We have subjected the results of the previous surveys of professional pedagogical motivation students [16] and received data of the internal factors studies of their professional development to mathematical processing of multiple correlation. This allowed us to determine a link between professional motivation and personal psychomotor peculiarities, intellectual and communicative spheres $(r=0,7241)$. Based on this, it is possible to state that the results of the internal factors of students' personality professional development diagnostics are influenced not only by compliance of their characterological features to the professional demands but also by the conscious professional interests. The studies of the influence of personal characterological peculiarities on professional self-determination dynamics [17] confirm validity of this work.

Undoubtedly, several formal dynamic properties of students' individuality can and should be influenced by various means in the process of study and training.
Specific properties of individuality are an integral part of the model characteristics of a specialist and significantly affect the physical and mental qualities. This requires their maintenance at a high enough level for the effective implementation of professional activities. Communication skills based on the properties of the communication domain of a teacher's activity also play an important role and belong to the organizational and pedagogical component of his/her competence.

Therefore, in the process of study and training of future teachers of physical education, it is necessary not only to identify the level of individual personality characteristics of students, but also to correct them. Firstly, this elates to those features that help to master the profession and facilitate the adaptation of students to their future work. Because of this, it is advisable to specifically develop not only student's psychomotor domain, but also the intellectual and communication domains. This would create the prerequisites for shaping their individual style of work.

We believe that the most highly influential factors for shaping the focus of a student's pedagogical work and professional development lie in the subjects of professional education. Thanks to which, professional interest rises, and vital work-related pedagogical qualities are formulated.

The study of the curricula of higher education institutions in the field of physical education and sports shows that for the entire period of study, sports-specialised subjects take up $50 \%$ of education, psycho-pedagogical training - approximately $20 \%$, and pedagogical and coaching training - approximately $8 \%$. We did not find evidence to support this type of curriculum. According to the UNESCO recommendations, the training of teachers should cover the natural sciences, foundations of philosophy, psychology, and sociology along with their connection with pedagogy. UNESCO also recommends the study of the theory and history of pedagogy, comparative pedagogy, schooling, teaching methods and the basics of experimental research in pedagogy, studying subjects related to the future field of teaching, pedagogical practices and internships $[18,19]$.In general, the training of teachers of physical education and coaches in Ukraine meets international requirements and standards. However, we consider it appropriate to change the ratio of educational subjects in favor of pedagogical subjects, since it is difficult to persuade students that psychopedagogical knowledge plays a fundamental role in the formation of professional competence, and the shaping and development of their pedagogical skills [20,21].

\section{Conclusion}

The study of internal factors of professional development in the future teacher of physical education and sports on an intrapersonal level has allowed us to conclude that: the set of individual factors was determined that influences the formation and professional development of teachers of physical education and sport. This set comprises from: temperament, character, 
abilities, specifics of interests, peculiarities of psychic processes and intellect, physical fitness. By psychomotor domain indicators, future physical education teachers and coaches do not have a great need for psychomotor activity, although they require it on a higher level compared to other students. We have determined the link between the general professional development and characteristics of psychomotor, intellectual and communicative spheres of the future teachers of physical education and sport and their compliance to the professional demands. The properties of various aspects of temperament like the dynamic side of the personality of the future teacher of physical education and sports in the intellectual and communication domains are insufficient for professional work and require targeted development of effective methods of professional education and psycho-pedagogical means of motivation.

\section{Conflict of interests}

The author declares that there is no conflict of interests.

\section{References}

1. Gynetsinsky VI. Fundamentals of theoretical pedagogy: textbook. St. Petersburg: Publishing House of St. Petersburg; 1992. (in Russian)

2. Psholovsky T. A small encyclopedia of praxeology and organizational theory. Wroclaw - Warzaw: National Institute Ossolinsky; 1978. (in Polish)

3. Serin H. The Use of Extrinsic and Intrinsic Motivations to Enhance Student Achievement in Educational Settings. International Journal of Social Sciences \& Educational Studies, 2018;5(1):191-194. https://doi.org/10.23918/ijsses.v5i1p191

4. Erbas MK. Determination of physical education teachers' educational beliefs. International Journal of Academic Research. 2013;5(5):386- 392. https://doi.org/10.7813/2075-4124.2013/5-5/B.60

5. Muros RB, Fernandez-Balboa JM. Physical education teacher educators' personal perspectives regarding their practice of critical pedagogy. Journal of Teaching in Physical Education, 2005;24:243- 264. https://doi.org/10.1123/jtpe.24.3.243

6. Morris M, Chrispeels J, Burke P. The Power of Two: Linking External with Internal Teachers' Professional Development. Phy Delta Kappan, 2003;84(10):764- 767. https://doi.org/10.1177/003172170308401010

7. Serin H. Developing the Teaching Profession Factors Influencing Teachers' Performance. International Journal of Social Sciences \& Educational Studies 2017;4 (2):10-14. 14. https://doi.org/10.23918/ijsses.v4i2sip10

8. Kennedy MM. How Does Professional Development Improve Teaching? Review of Educational Research, 2016;86(4): 945-980. https://doi.org/10.3102/0034654315626800

9. Wood K, Jaidin H, Jawawi R, Perera JS. How and what teachers learn from collaborative professional development. International Journal of Lesson and Learning Studies, 2017; 6(2):151-168. https://doi.org/10.1108/IJLLS-09-2016-0028

10.Romar JE, Aström P, Ferry M. Practical knowledge of preservice physical education teachers: Content and influence of acculturation. Journal of Physical Education and Sport, 2018;15:114-126.

11.GrauV,CalcagniE,PreissDD.\&OrtizD.Teachers'professional development through university-school partnerships:
Theoretical standpoints and evidence from two pilot studies in Chile. Cambridge Journal of Education, 2017;47(1):19-36. https://doi.org/10.1080/0305764X.2015.1102867

12.Girvan G, Conneely C, \& Tangney B. Extending experiential learning in teacher professional development. Teaching and Teacher Education, 2016;58:129-139. https://doi.org/10.1016/j.tate.2016.04.009

13.Mohan PP, Chand DD, \& Lingam GI. Teachers' perceptions of the impact of professional development on learning and teaching in a developing nation. Australian Journal of Teacher Education, 2017;42(11):18-33. https://doi.org/10.14221/ajte.2017v42n11.2

14.Ilyin EP. Psychology of individual differences. Sankt Petersburg: Peter; 2011. (in Russian)

15.Rusalov VM. Temperament in the structure of human individuality. Differential psychophysiological and psychological research. Moscow: Institute of Psychology, Russian Academy of Sciences; 2012. (in Russian)

16.Fokkens-Bruinsma M, \& Canrinus E. Motivation to become a teacher and engagement to the profession. Evidence from different contexts. International Journal of Educational Research, 2014; 65:65-74. https://doi.org/10.1016/j.ijer.2013.09.012

17.Kudryavtsev TV, Sukharev AV. The influence of personality traits on the dynamics of professional self-determination. Questions of psychology, 1985;1:86-94. (in Russian)

18.Freeney EJ. How an orientation to learning influences the expansive-restrictive nature of teacher learning and change. Teacher Development, 2016;20(4):458-481. https://doi.org/10.1080/13664530.2016.1161659

19.Villegas - Reimers E. Teacher professional development: an international review of literature. UNESKO: International Institute for Educational Planning; 2003.

20.Cravens X, Drake TA, Goldring E. Teacher peer excellence groups (TPEGs). Building communities of practice for instructional improvement. International Journal of Lesson and Learning Studies, 2017;55(5):283- 292. https://doi.org/10.1108/JEA-08-2016-0095

21.Van Driel JH., \& Berry AK. Teacher professional development focusing on pedagogical content knowledge. Educational Researcher, 2012;41(1):26-28. https://doi.org/10.3102/0013189X11431010 


\section{Information about the authors:}

Stepanchenko N.I. (Corresponding author); Doctor of Pedagogical Sciences, Docent, Professor; https://orcid.org/0000-00033405-7024; pp@ldufk.edu.ua; Department of Pedagogy and Psychology, Lviv State University of Physical Culture named after I. Bobersky; 11, Kostiushko, Str., Lviv, 79000, Ukraine.

Briskin Y. A.; Doctor of Sciences of Physical Education and Sports, Professor ; https://orcid.org/0000-0001-6375-9872; tmos@ Idufk.edu.ua; Department of Theory of Sport and Physical Culture, Lviv State University of Physical Culture named after I. Bobersky; 11, Kostiushko, Str., Lviv, 79000, Ukraine.

\section{Cite this article as:}

Stepanchenko NI, Briskin YA. Dispositional factors of personality professional development of the future teachers of physical education and sport. Physical education of students, 2019;23(4):202-208.

https://doi.org/10.15561/20755279.2019.0407

This is an Open Access article distributed under the terms of the Creative Commons Attribution License, which permits unrestricted use, distribution, and reproduction in any medium, provided the original work is properly cited http://creativecommons.org/licenses/by/4.0/deed.en

Received: 04.07.2019

Accepted: 08.08.2019; Published: 28.08.2019 